\title{
Long term field sampling in Sweden reveals a shift in occurrence of cytochrome $b$ genotype and amino acid substitution F129L in Alternaria solani, together with a high incidence of the G143A substitution in Alternaria alternata
}

\author{
E. Edin $(\mathbb{D} \cdot$ E. Liljeroth • B. Andersson
}

Accepted: 21 June 2019 /Published online: 8 July 2019

(C) The Author(s) 2019

\begin{abstract}
The incidence of the pathogenic fungus Alternaria solani on potato during the years 2009 to 2016 was analysed and the distribution of the two genotypes of cytochrome $b$ (genotype 1, GI and genotype 2, GII) determined. Potato leaflets with lesions resembling early blight were collected in August and September 2009-2016 in the south-eastern part of Sweden and during 2010 and 2012-2014 in the central part of Sweden. In total, 2042 potato leaflet samples were analysed using diagnostic PCR methods. Alternaria solani was more commonly found in the samples collected later in the growing seasons. The occurrence of substitutions in the gene encoding cytochrome $b$, associated with loss of sensitivity towards strobilurins, was determined by sequencing a segment in the target gene in all confirmed A. solani samples. The proportion of A. solani GI decreased in relation to GII over the years. All except five GI samples were non-mutated. Genotype 2 was already present in the first year of sampling but only one sample possessed the F129 L substitution. A distinct shift from
\end{abstract}

Electronic supplementary material The online version of this article (https://doi.org/10.1007/s10658-019-01798-9) contains supplementary material, which is available to authorized users.

E. Edin $(\bowtie) \cdot$ B. Andersson

Department of Forest Mycology and Plant Pathology, Swedish University of Agricultural Sciences, P.O. Box 7026, SE 750

07 Uppsala, Sweden

e-mail: eva.edin@slu.se

\section{E. Liljeroth}

Department of Plant Protection Biology, Swedish University of Agricultural Sciences, P.O. Box 102, SE 23053 Alnarp, Sweden non-mutated GII to GII F129 L was observed between the season of 2011-2012 and a similar shift occurred in the pathogen population from GI to GII between 2012 and 2013. Identification of Alternaria alternata was performed during 2009-2013. The species was most often in co-occurrence with A. solani. Most of the samples investigated possessed the G143A substitution associated with strobilurin resistance.

Keywords Distribution · Fungicide resistance Monitoring $\cdot$ Potato $\cdot$ Strobilurin

\section{Introduction}

Early blight is a common potato disease in the southeastern part of Sweden but is also reported from other areas of the country. The plant-pathogenic fungus Alternaria solani is considered to be the main causal agent of early blight on potato in Europe (Spoelder et al. 2014; Stammler and Tegge 2014; Odilbekov et al. 2016), even though other species of Alternaria, such as Alternaria alternata, A. arborescens and A. grandis, were commonly found on leaflets with symptoms of early blight in Belgium (Vandecasteele et al. 2018; Landschoot et al. 2017b).

During the last decade, two versions of mitochondrial DNA encoding cytochrome $b$ in A. solani, genotype 1 (GI) and genotype 2 (GII), have been reported from Europe (Leiminger et al. 2014; Odilbekov et al. 2016). The GI genotype is referred to as the European version, present in European countries. The GII genotype, which 
was first reported in populations in USA and Canada, lack an intron in the gene encoding cytochrome $b$ when compared to the GI genotype (Pasche et al. 2005; Peters et al. 2008). Accordingly, the GII genotype in Europe is often referred to as the American version. The GII version can be identified using PCR primers, which were initially developed for identifying a mutation associated with reduced sensitivity to strobilurins in the American population of $A$. solani (Pasche et al. 2005). The substitution is referred to as F129 L since the amino acid phenylalanine is changed to leucine at codon position 129 in the gene encoding cytochrome $b$. Many of the analysed GII samples from Germany, Belgium and Sweden possessed the F129 L substitution, here referred to as GII F129 L (Leiminger et al. 2014; Odilbekov et al. 2016; Landschoot et al. 2017a). Three different nucleotide substitutions where the wild type codon TTC has changed to CTC, TTA or TTG, leading to the same amino acid substitution, have been found (Pasche et al. 2005). These substitutions result in a reduced field efficacy of strobilurins in A. solani, which has been confirmed in in-vitro sensitivity tests (Rosenzweig et al. 2008a; Pasche et al. 2005; Landschoot et al. 2017a). In Sweden, field observations of reductions in field efficacy of strobilurins have been made since 2014. This is especially the case in the area around Kristianstad in south-eastern Sweden where severe epidemics of early blight have been observed, despite repeated applications of strobilurin-based fungicides (Odilbekov et al. 2016; Liljeroth 2016). Analysis of samples from a fungicide treated experimental field site in 2014 revealed that almost all isolates had the F129 L substitution (Odilbekov 2015).

Loss of sensitivity against strobilurins in A. alternata is due to an amino acid substitution at codon position 143 (G143A, glycine to alanine) (Luo et al. 2007; Vega and Dewdney 2014), resulting in complete resistance against the fungicide (www.frac.info). In the A. solani genome, an intron is located immediately after the codon for glycine at position 143 (Grasso et al. 2006). Any substitution occurring there seems to be lethal to the organism, explaining why there are no reports of the G143A substitution in A. solani (Grasso et al. 2006).

Both A. solani and A. alternata were identified in Swedish field trials during 2005 and 2006, with A. solani being the more abundant species (Andersson and Wiik 2008). During the last decades, problems with early blight have increased in the south-eastern part of Sweden, especially in starch potato crops. The disease occurs in all parts of Sweden where potato is grown but is much less of a problem in other regions of the country.

The aim of this project was to determine the incidence of $A$. solani in lesions resembling early blight on potato in the south-eastern and central parts of Sweden during 2009-2016 using diagnostic PCR that enables the identification of the mitochondrial genotypes GI or GII. We also aimed to describe temporal changes regarding genotype distribution and presence of mutations associated with reduced sensitivity to strobilurins. In addition, analyses of incidence of $A$. alternata were performed in 2009-2013 and the presence of the substitution G143A in the gene encoding cytochrome $b$ were analysed in the samples positive for A. alternata from 2011 and 2012.

\section{Materials and methods}

\section{Sampling}

Potato leaflets with symptoms resembling early blight were sampled in 119 potato fields from southern and central potato growing areas in Sweden during 20092016 (Fig. 1; Table 1). Leaflets were placed in small paper bags, air dried and stored until DNA extraction.

Three series of sampling strategies were used:

I. Sampling was performed yearly at four specific farms, Öland A, Kalmar B, Kristianstad C and Kristianstad D, in the south-eastern part of Sweden during 2009-2016 (Table 1A, $N=826$ ). The starch potato cultivar Kuras was grown every year in all sampled fields.

II. Sampling of forty-seven randomly chosen potato fields in southern Sweden was performed during 2010-2015 to follow the population changes in southern Sweden (Table 1B; $N=648$ ). In most of these fields starch potato cultivars, viz. Kuras, Kardal, Burana or Elkana, were grown. Three of the fields were used for organic potato production.

III. Forty ware potato fields in central Sweden (counties of Västergötland, Östergötland, Närke, Värmland and Dalarna) with reported outbreaks of early blight were sampled during 2010 and 2012-2014 (Table $1 C, N=568$ ). In central Sweden, organic and conventional ware potato crops were in most cases sampled once per growing season, usually in August. The main cultivars were Fakse, Inova, King Edward VII, Melody and Perlo. 
Fig. 1 Map of Sweden representing the counties of collection and locations of the four farms where collections were made every year between 2009 and 2016

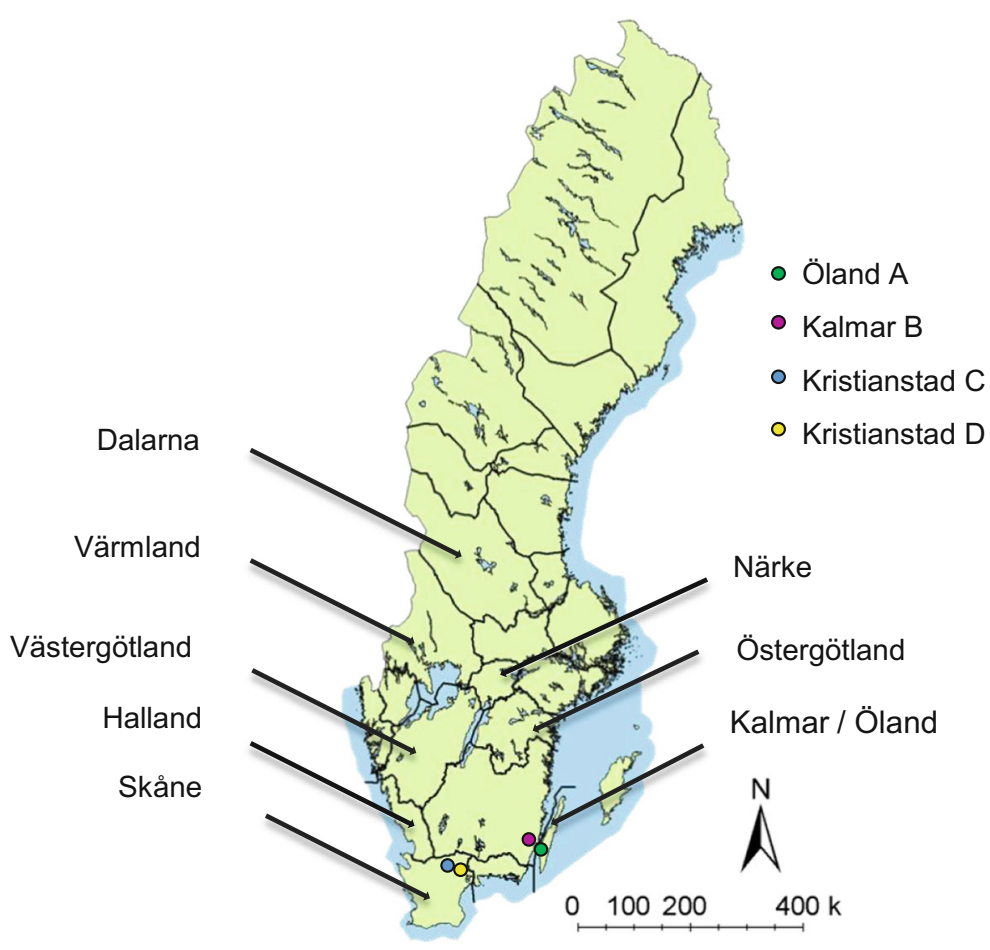

samples collected in central Sweden each year divided by county. Fields in strategy I, II and III sampled more than once during a season are included in Tables 3 and 5
Table 1 Sampling strategy of potato leaflets with symptoms of early blight during 2009-2016. I: number of samples collected 1-3 times per season at four farms, II: number of samples collected in southern Sweden each year divided by county and III: number of

\begin{tabular}{|c|c|c|c|}
\hline Region & 2009 & 201 & 20 \\
\hline
\end{tabular}

and sum of samples

\begin{tabular}{|c|c|c|c|c|c|c|c|c|c|c|}
\hline \multicolumn{11}{|l|}{ I Farm } \\
\hline Öland A & Kalmar/Öland & 48 & 8 & 12 & 8 & 8 & 8 & 8 & 8 & 8 fields $^{\mathrm{b}}, N=108$ \\
\hline Kalmar B & Kalmar/Öland & $72^{\mathrm{a}}$ & $72^{\mathrm{a}}$ & $72^{\mathrm{a}}$ & 32 & 8 & 8 & 8 & 8 & 8 fields, $N=280$ \\
\hline Kristianstad C & Skåne & $72^{\mathrm{a}}$ & 8 & 12 & 8 & 16 & 8 & 8 & 10 & 8 fields, $N=142$ \\
\hline Kristianstad D & Skåne & $72^{\mathrm{a}}$ & $72^{\mathrm{a}}$ & $72^{\mathrm{a}}$ & 32 & 16 & 16 & 8 & 8 & 8 fields, $N=296$ \\
\hline \multicolumn{11}{|l|}{ II Southern Sweden } \\
\hline Öland & Kalmar/Öland & & & & & 8 & 4 & 8 & & 3 fields, $N=20$ \\
\hline Kalmar & Kalmar/Öland & & $72^{\mathrm{a}}$ & & 8 & 16 & 4 & & & 5 fields, $N=100$ \\
\hline Skåne & Skåne & & 96 & 96 & 72 & 88 & 56 & 64 & & 32 fields, $N=472$ \\
\hline Halland & Halland & & & & & 8 & 24 & 24 & & 7 fields, $N=56$ \\
\hline \multicolumn{11}{|l|}{ III Central Sweden } \\
\hline Västergötland & Central Sweden & & 48 & & 40 & 144 & $88^{\mathrm{a}}$ & & & 23 fields, $N=320$ \\
\hline Östergötland & Central Sweden & & 48 & & 32 & & $112^{\mathrm{a}}$ & & & 10 fields, $N=192$ \\
\hline Närke / Dal./ Värml. & Central Sweden & & & & 16 & 32 & 8 & & & 7 fields, $N=56$ \\
\hline \multicolumn{2}{|l|}{ Sum of samples each year } & 264 & 424 & 264 & 248 & 344 & 336 & 128 & 34 & 2042 \\
\hline
\end{tabular}

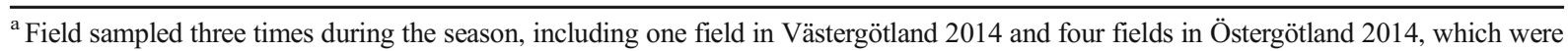
used for within-season analysis

${ }^{\mathrm{b}}$ Total number of fields sampled at each location or county, respectively 
The distance between the fields in Skåne ranged from $4 \mathrm{~km}$ to $70 \mathrm{~km}$, whereas the distance between the regions of Skåne and Kalmar/Öland is approximately $150 \mathrm{~km}$. Between Skåne and Halland this distance is about $100 \mathrm{~km}$, while the distance between the two regions in south and central Sweden is approximately $320 \mathrm{~km}$.

Samples were collected one to three times each season; at the beginning of August, the end of August and in mid-September. The majority of the samples were collected at the end of August, especially in fields that were sampled only once per season. From each field, 8 24 leaflets were sampled at each occasion. When sampling 24 leaflets per occasion, the collection was performed along four lines separated by eight potato rows ( $\sim 6 \mathrm{~m})$. In each line, samples were collected at six points, approximately ten meters apart. Collection of twelve or sixteen samples per field was made in two lines, with eight rows in between, at two occasions within the season. When eight samples per field were analysed, the leaflets were randomly collected in a section of the field. DNA from single spore isolates from the farms Kristianstad C $2011(N=12)$ and Kristianstad E $2014(N=8)$ was extracted according to Odilbekov et al. (2016). The analyses of abundance for A. alternata were performed using the same DNA samples as for A. solani from fields in southern Sweden analysed during 2009-2012. Potato advisors asked specifically for identification of both A. alternata and A. solani in samples collected in nine fields in central Sweden during 2012 and 2013.

All sampled fields in southern Sweden (except the organic ones) had been treated at least once with strobilurins prior to sampling. Most of the fields were treated against early blight two to four times, depending on the fungicide used, azoxystrobin or pyraclostrobin in combination with boscalid. Approximately half of the fields sampled in the central part of Sweden were treated with strobilurins.

In addition, four to eight leaves from black nightshade (Solanum nigrum) with lesions similar to early blight were collected in August or September 2011, 2012 and 2015 at the farms Öland $A$ and/or Kristianstad D.

\section{DNA extraction}

Leaf discs (5 $\mathrm{mm}$ in diameter) containing one single lesion were cut out from each leaflet, washed twice in sterile distilled water and dried with paper towels. All discs were cut to include both green and necrotic tissue. The discs were homogenised using five glass beads ( $3 \mathrm{~mm}$ ) in a $2 \mathrm{ml}$ micro centrifuge tube and shaken at 5500 repeats per minute during $30 \mathrm{~s}$ in a Precellys ${ }^{\circledR} 24$ Bead Mill Homogenizer (Bertin Technologies). Eight hundred $\mu$ of extraction buffer (3\% CTAB-EDTA, $\mathrm{pH}$ 8) was added and the samples were again shaken as described above. The CTAB-EDTA protocol was followed onwards (Ihrmark et al. 2002) and the DNA pellet was re-suspended in $30 \mu \mathrm{l}$ distilled water. The samples were diluted 1:10 prior to further analyses. From 2013, an E.Z.N.A.® Plant DNA Extraction kit was used (Omega Bio-Tek, Norcross, GA USA). The samples were homogenised as above using the extraction buffer 1 in the second step. At elution, $35 \mu \mathrm{l}$ of buffer was added twice to the spin column containing the bound DNA and the same $1.5 \mathrm{ml}$ tube was used in both spins, resulting in $70 \mu \mathrm{l}$ of DNA-solution.

Species identification

All samples were tested for presence of $A$. solani by PCR analyses, which also enabled identification of cytochrome $b$ genotype GI or GII (Table 2). The PCR conditions for the $10 \mu \mathrm{l}$ reaction were $2.75 \mathrm{mM} \mathrm{MgCl}_{2}$ (final concentration), $0.2 \mathrm{mM}$ dNTP, $0.2 \mu \mathrm{M}$ of each

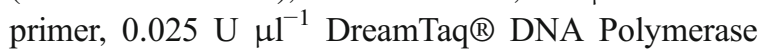
(Fermentas International Ink, Canada) and $10 \mathrm{X}$ DreamTaq ${ }^{\mathrm{TM}}$ Green Buffer. The PCR conditions were $95^{\circ} \mathrm{C}$ for $2 \mathrm{~min}, 40$ cycles of $30 \mathrm{~s}$ at $95^{\circ} \mathrm{C}, 30 \mathrm{~s}$ at $60^{\circ} \mathrm{C}$ (GI) or $54{ }^{\circ} \mathrm{C}$ (GII) and $30 \mathrm{~s}$ at $72{ }^{\circ} \mathrm{C}$, followed by a 7 min extension. All samples were analysed twice with a positive (mycelium DNA) and negative control (distilled water) included in every run. The PCR products were separated on $1.0 \%$ agarose gel stained with $0.01 \mu \mathrm{ml}^{-1}$ Nancy-520 DNA Gel Stain (Sigma-Aldrich), full strength $\mathrm{SB}$, at $12 \mathrm{~V} \mathrm{~cm}^{-1}$ for $25 \mathrm{~min}$.

The presence of A. alternata was analysed in all samples from 2009 to 2012 but only in samples from central Sweden in 2013. The identification of A. alternata was performed using either of two PCR methods developed by Zur et al. (2002) or Vega and Dewdney (2014), where the latter one was used for samples collected in 2012 and 2013 (Table 2). The PCR conditions were the same as for A. solani, except that the annealing temperatures were set according to the references. 
Table 2 Primers used for identification of cytochrome $b$ genotype in Alternaria solani, which also reveals occurrence of the amino acid substitution F129 L and identification of Alternaria alternata and the amino acid substitution G143A

\begin{tabular}{llll}
\hline Primer & Primer name & Primer sequence (5' to 3') & Reference \\
\hline A. solani, genotype 1, GI & Asol 129(319 & ATGCGGGTGAATACGGTTAA & Edin (2012) \\
& 143 Reverse primer & CTCTACTTTGTTTATGTTATTTAACCAAGAATG & Rosenzweig et al. (2008a) \\
A. solani genotype 2, GII & AS-5F & AGAACTCTAGTATGAACTATTGG & Pasche et al. (2005) \\
& AS-5R & ACTTCTTGTAGAATATCCTCTTT & Pasche et al. (2005) \\
A. alternata ITS & Aalt-F & GGCGGGCTGGAACCTCTCGG & Zur et al. (2002) \\
& Aalt- $R$ & AATGGATGCTAGACCTTTGC & Zur et al. (2002) \\
A. alternata G143A & Cytb2f & CTATGGATCTTACAGAGCAC & Vega and Dewdney (2014) \\
& DTRcytb2-INTr & GTATGTAACCGTCTCCGTC & (2014) \\
\hline
\end{tabular}

Amino acid substitutions

To detect any substitution associated with loss of sensitivity to strobilurins in all samples determined as A. solani (either GI or GII), the PCR products from a reaction volume of $50 \mu \mathrm{l}$ with the same primers and conditions as above were sequenced. The PCR-products included the amino acid positions $129,137 \& 143$ in the gene encoding cytochrome $b$. The products were purified using Agencourt AMPure XP (Beckman Coulter, MA, USA) according to the manufacturer's manual and sent for sequencing (Macrogen Inc. Seoul, Korea). Only data from successfully sequenced samples is reported in tables and figures.

The occurrence of G143A in A. alternata among a subset of the samples from 2011 and 2012 was analysed using a method originally developed for identification of the pathogen in citrus, which was the same primer set as for identification of A. alternata (Vega and Dewdney 2014). The PCR conditions for the $20 \mu \mathrm{l}$ reaction were as for $A$. solani except that the annealing temperature was $59{ }^{\circ} \mathrm{C}$. The presence of the G143A substitution was tested using Cleaved Amplified Polymorphic Sequences (CAPS) where the PCR product was digested into two pieces of approximately $150 \mathrm{bp}$ and $270 \mathrm{bp}$, respectively, using the restriction enzyme SatI (Fnu4HI) (Thermo Scientific). The reaction volume of $10 \mu \mathrm{l}$ containing $5 \mathrm{U}$ of enzyme solution and $5 \mu$ of PCR product solution was incubated in a $37{ }^{\circ} \mathrm{C}$ water bath for 2 hours. The PCR products were separated on a $1.5 \%$ agarose gel as above. The whole analysis was performed two to three times to obtain reliable results.
Statistical analyses

Logistic regression was used to determine changes in the pathogen populations within seasons and between years. The least square means of the log-odds were compared $(p<0.05)$. For interpretation, the predicted probabilities of observing the pathogens and genotypes are given. Adjustments for multiple comparisons were done according to Tukey-Kramer. All statistical analyses were performed in SAS 9.4 (SAS Institute, Cary, USA).

Seasonal changes in abundance of A. solani (Table 3) were identified by analysing lesions on leaflets from sampling strategies I, II and III from fields that were sampled three times during the same season. Samples from eight fields in southern Sweden collected during 2009-2011 and five fields in central Sweden collected in 2014, were used for statistical analyses of within season changes for occurrence of $A$. solani by using logistic regression to calculate the probability of a sample being positive for the pathogen. Seasonal changes in the probability of a sample being positive for A. alternata were calculated using samples from five fields sampled three times during a season in 2010 or 2011 (sampling strategy I, Table 4).

Logistic regression was also used to analyse differences between sampling year in probability of a sample of A. solani being genotype GI and genotype GII F129 L among samples collected at the end of August 20092016, originating from southern Sweden. The probability of a sample positive for A. alternata possessing the substitution G143A was estimated using samples analysed for G143A. 


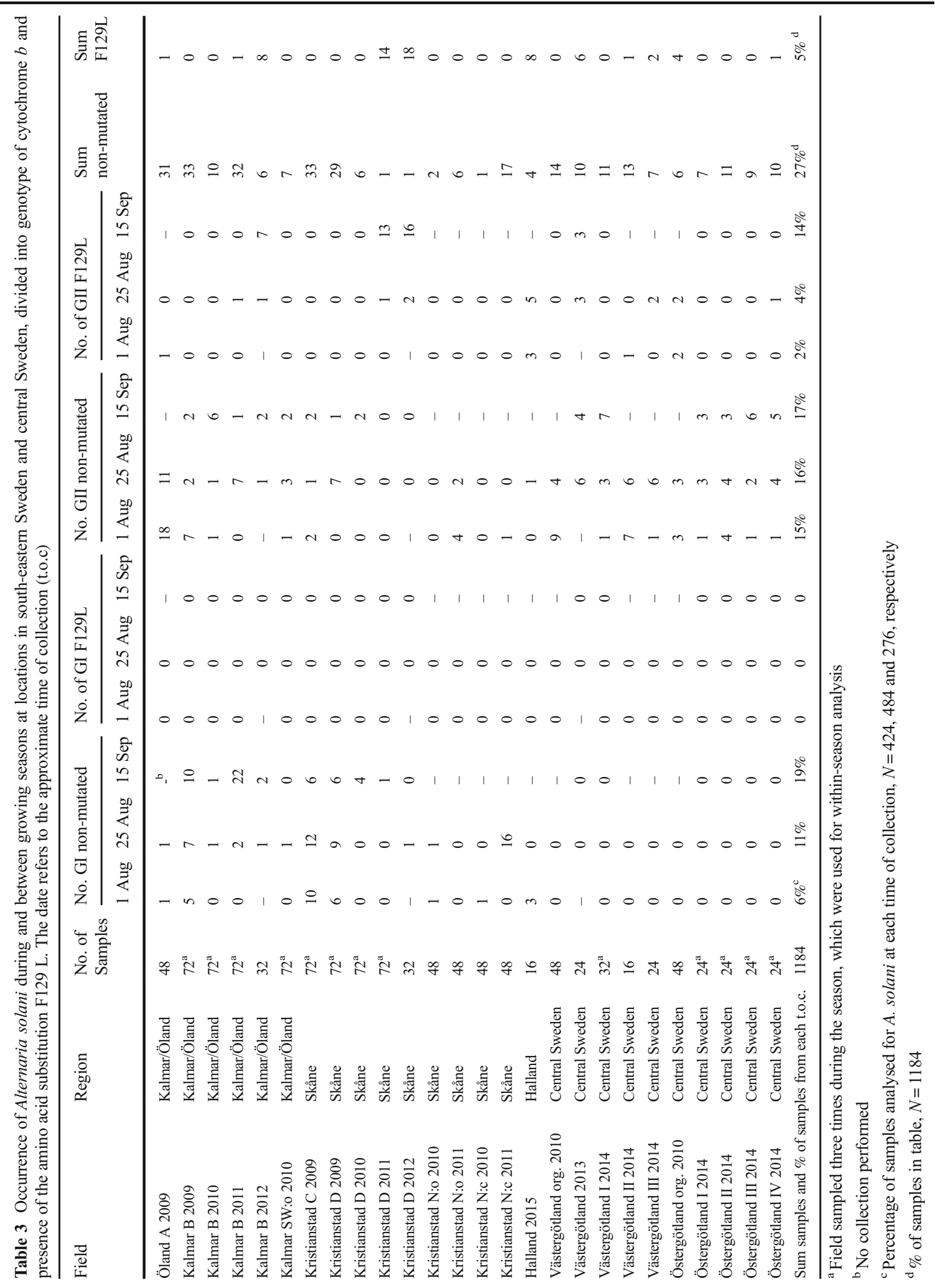




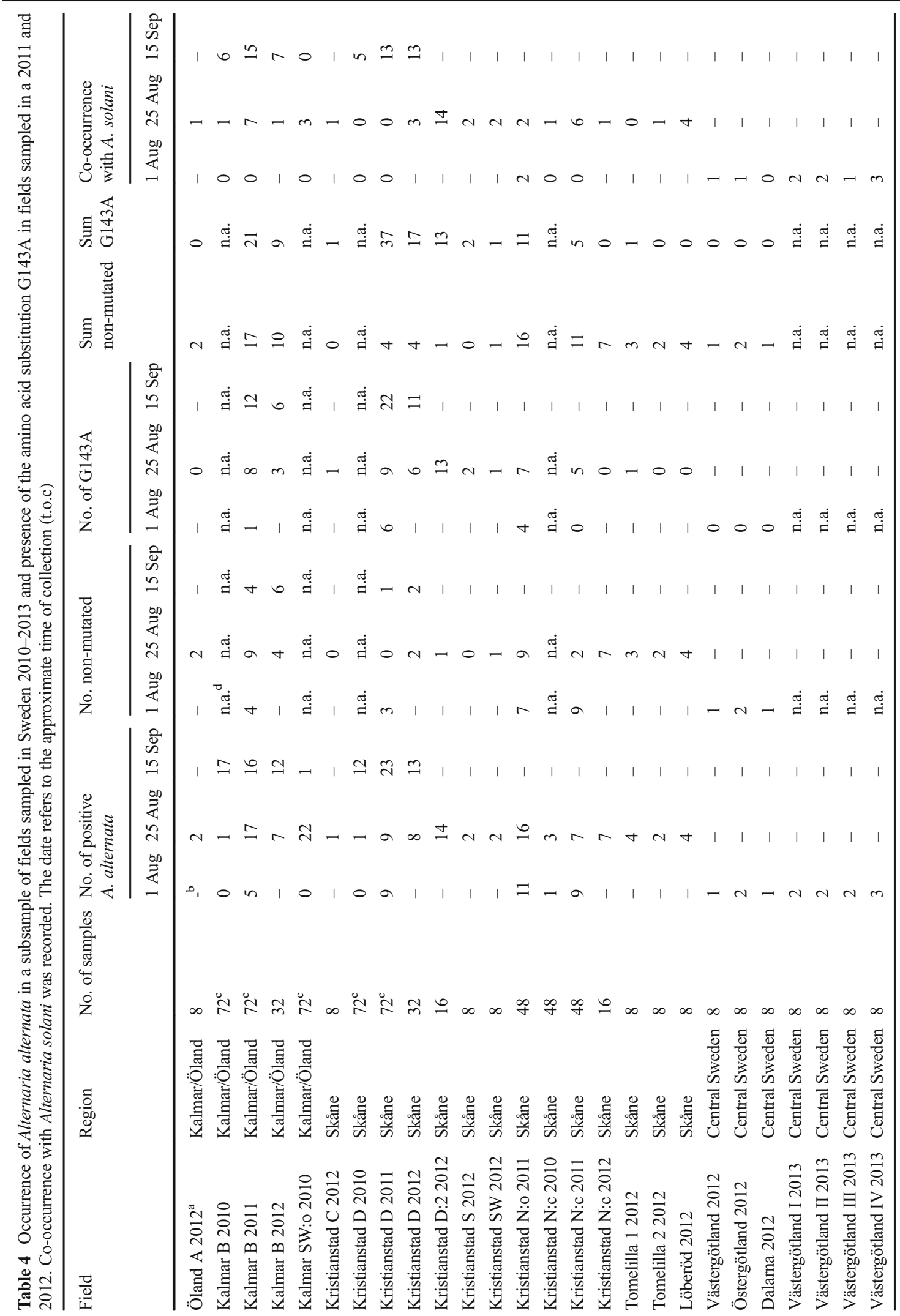


Regional differences for both species, and population changes between years for A. alternata, could not be determined statistically due to imbalanced datasets.

\section{Results}

Within season population changes in occurrence of A. solani and A. alternata

The incidence of lesions resembling early blight increased in the fields during all growing seasons (not shown). For all sampling years, A. solani GI or GII was found in the majority of the lesions sampled in September (Table 3 ). The probability of a sample being positive for $A$. solani increased significantly for each sampling occasion in the eight fields collected three times during the seasons 2009-2011 in southern Sweden $(p<0.0001)$, but this difference was less clear for the samples from central Sweden 2014 ( $p=0.0107$; Table 5).

Alternaria alternata was often found in co-occurrence with A. solani (Table 4). The probability of lesions being positive for A. alternata increased significantly for each sampling occasion in the five fields sampled three times during the season $(p<0.0001$; Table 5).

Population changes between years of $A$. solani and occurrence of A. alternata

During the first year of sampling, A. solani GI was more common than GII except at the farm Öland A where the proportion of GII was high already in August 2009 (Fig. 2; Table 3). The abundance of GI in southern Sweden decreased significantly during the years among samples from the second collection $(p<0.0001)$ with a shift to GII between the years 2012 and 2013 (Table 6). However, at the farm Kristianstad D, the ratio between GI and GII changed drastically already between 2010 and 2011 (Fig. 2). Alternaria solani was identified in $47 \%$ of the samples from central Sweden and $95 \%$ of those were of the GII genotype (Fig. 3).

Alternaria alternata was not recovered from any sample collected in 2009, but the species was identified in $277(38 \%)$ of the total number of samples analysed during 2010-2013 and 127 of these were found in cooccurrence with $A$. solani (Table 4). Only a few samples from central Sweden were positive for A. alternata. 
Table 5 Seasonal changes in probability for occurrence of samples positive for Alternaria solani and Alternaria alternata, the probability of a sample of A. solani GII carrying the F129 L substitution and a sample positive for A. alternata carrying the
G143A substitution (LSM = least square means, $S E=$ standard error). Different letters indicate significant differences within each column $(p<0.05)$

\begin{tabular}{|c|c|c|c|c|c|c|c|c|c|c|c|c|c|c|c|}
\hline \multirow[t]{2}{*}{ Time of collection } & \multicolumn{3}{|c|}{$\begin{array}{l}\text { Prob. of A. solani } \\
\text { Southern Sweden }\end{array}$} & \multicolumn{3}{|c|}{$\begin{array}{l}\text { Prob. of A. solani } \\
\text { Central Sweden }\end{array}$} & \multicolumn{3}{|c|}{$\begin{array}{l}\text { Prob. of A. solani } \\
\text { GII F129L }{ }^{b}\end{array}$} & \multicolumn{3}{|c|}{$\begin{array}{l}\text { Prob. of } \\
\text { A. alternata }\end{array}$} & \multicolumn{3}{|c|}{$\begin{array}{l}\text { Prob. of A. alternata } \\
\text { G143A }{ }^{\mathrm{c}}\end{array}$} \\
\hline & LSM & SE & & LSM & SE & & LSM & SE & & LSM & $\mathrm{SE}$ & & LSM & SE & \\
\hline Beginning of August & 0.276 & 0.03 & $\mathrm{a}$ & 0.200 & 0.06 & $\mathrm{a}$ & 0 & 0 & $\mathrm{a}$ & 0.116 & 0.03 & $\mathrm{a}$ & 0.324 & 0.08 & $\mathrm{a}$ \\
\hline End of August & 0.396 & 0.04 & $b$ & 0.438 & 0.07 & $a b$ & 0.009 & 0.06 & $\mathrm{a}$ & 0.417 & 0.05 & $\mathrm{~b}$ & 0.549 & 0.05 & $\mathrm{a}$ \\
\hline Mid-September & 0.651 & 0.03 & $\mathrm{c}$ & 0.500 & 0.08 & $\mathrm{~b}$ & 0.448 & 0.09 & $\mathrm{~b}$ & 0.575 & 0.05 & $\mathrm{c}$ & 0.797 & 0.05 & $\mathrm{~b}$ \\
\hline No. of samples analysed & 576 & & & 128 & & & 63 & & & 360 & & & 204 & & \\
\hline
\end{tabular}

${ }^{\text {a }}$ Samplings occurred approximately 1 week earlier in central Sweden due to maturation of the ware potato crops

${ }^{\mathrm{b}}$ Probability of GII F129 L among samples of A. solani GII originating from fields in southern Sweden collected three times

${ }^{\mathrm{c}}$ Probability of G143A among samples positive for A. alternata analysed for occurrence of G143A

Occurrence of the F129 L and G143A substitutions

Almost all sequenced samples with confirmed $A$. solani GI from the 8 years possessed the non-mutated version of the gene encoding cytochrome $b$. One sample of $A$. solani GI F129 L (codon CTC) was recovered from each of five fields sampled in 2013, 2014 and 2016 (Figs. 2 and 3).
The first sample of $A$. solani GII F129 L (codon TTA) was observed on the farm Öland A in 2009 and another sample of A. solani GII F129 L was found at the same farm in 2010. Isolates of the GII genotype, many of them with F129 L (codon TTA), were commonly found in 2011 at the farm Kristianstad D in Skåne and dominated in the area from then on (Figs. 2 and 3). Samples of

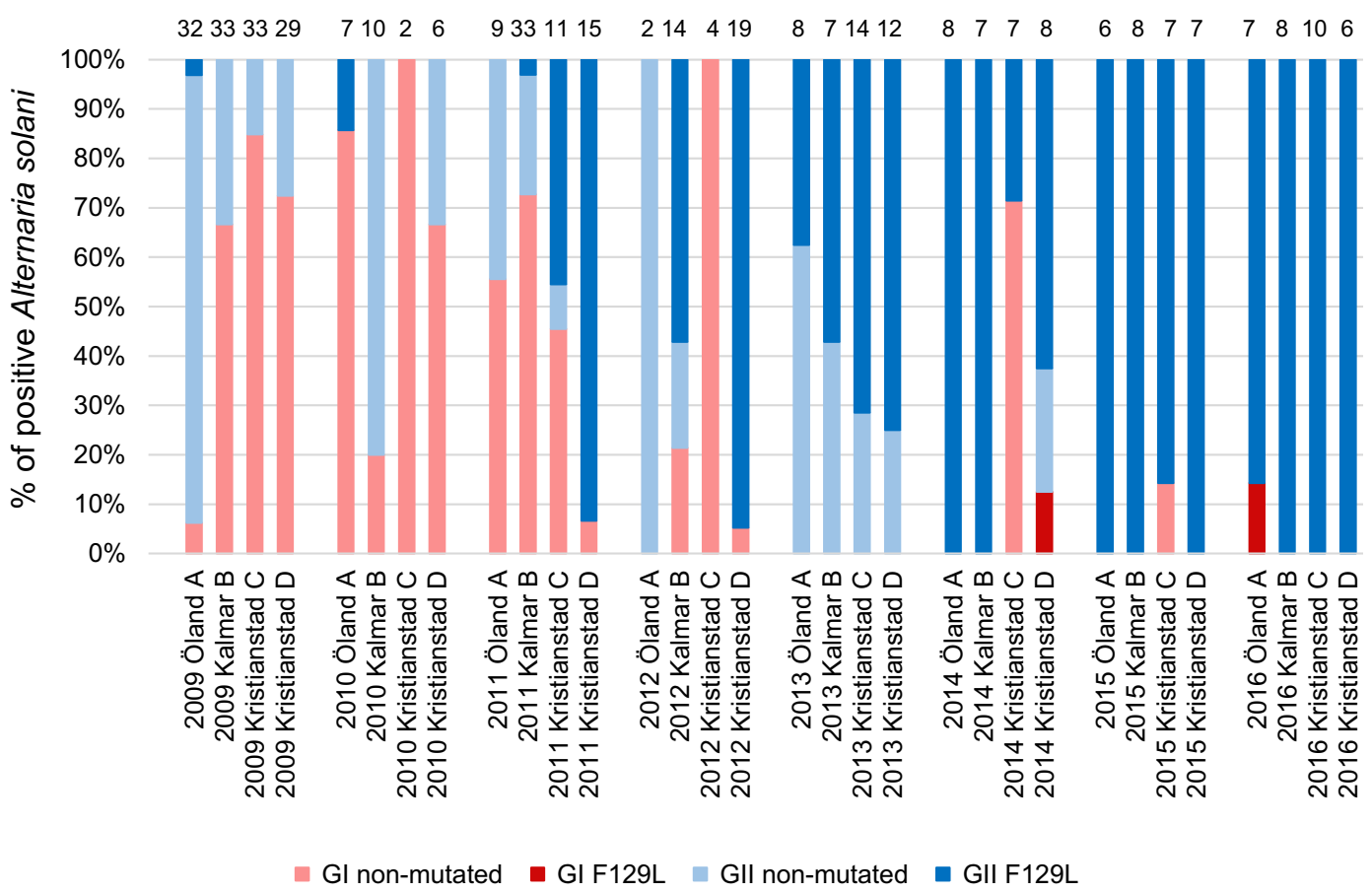

Fig. 2 Proportion of cytochrome $b$ genotype and presence of the amino acid substitution F129 L, associated with loss of sensitivity to fungicides based on strobilurins, among samples positive for
Alternaria solani collected at four farms during 2009-2016. The number above the bars represents the total number of positive samples each year 
Table 6 Temporal changes in probability for occurrence of cytochrome $b$ genotype 1 (GI) among samples positive for Alternaria solani collected in southern Sweden at the end of August and the probability of a genotype 2 (GII) sample possessing the F129 L substitution associated with loss of sensitivity towards strobilurins. (LSM = least square means, $\mathrm{SE}=$ standard error). Different letters indicate significant differences within each column $(p<0.05)$

\begin{tabular}{|c|c|c|c|c|c|c|}
\hline \multirow[t]{2}{*}{ Year of collection } & \multicolumn{3}{|c|}{ Prob. of GI } & \multicolumn{3}{|c|}{ Prob. of GII F129 L } \\
\hline & LSM & SE & & LSM & SE & \\
\hline 2009 & 0.580 & 0.07 & $\mathrm{a}$ & 0 & 0 & $\mathrm{a}$ \\
\hline 2010 & 0.500 & 0.16 & $\mathrm{a}$ & 0.200 & 0.18 & a \\
\hline 2011 & 0.318 & 0.10 & $\mathrm{a}$ & 0.133 & 0.09 & $\mathrm{a}$ \\
\hline 2012 & 0.439 & 0.07 & $\mathrm{a}$ & 0.844 & 0.06 & $\mathrm{~b}$ \\
\hline 2013 & 0.027 & 0.02 & $\mathrm{~b}$ & 0.685 & 0.04 & $\mathrm{~b}$ \\
\hline 2014 & 0.129 & 0.04 & $\mathrm{~b}$ & 0.590 & 0.06 & $b$ \\
\hline 2015 & 0.031 & 0.02 & $\mathrm{~b}$ & 0.887 & 0.04 & $\mathrm{~b}$ \\
\hline 2016 & 0.045 & 0.04 & $\mathrm{~b}$ & 1 & 0 & $\mathrm{~b}$ \\
\hline No. of samples analysed & 652 & & & 477 & & \\
\hline
\end{tabular}

A. solani GII F129 L increased significantly during the years among samples from the second collection originating from southern Sweden $(p<0.0001)$ with a clear shift towards GII dominance between the years 2011 and 2012 (Table 6). One sample with genotype A. solani GII F129 L (codon CTC) was found at the farm Kalmar B in 2014 and another one in the following year.

In central Sweden, samples of the GII genotype dominated, whereof 22\% carried the F129 L substitution (Fig. 3). The genotype GII F129 L was found in an organically cultivated field in 2010 in the county of Östergötland in the central part of Sweden (Table 3; Fig. 3).

Presence of both GI and GII in the same sample, even after multiple PCR and consecutive sequencing, was observed among the samples from 2009 and in some samples from other years (Supplementary Table 1). The combination non-mutant GI and non-mutant GII was the most common among the 111 samples with both genotypes, even though other combinations were occasionally found. The first two samples with the combination of non-mutant

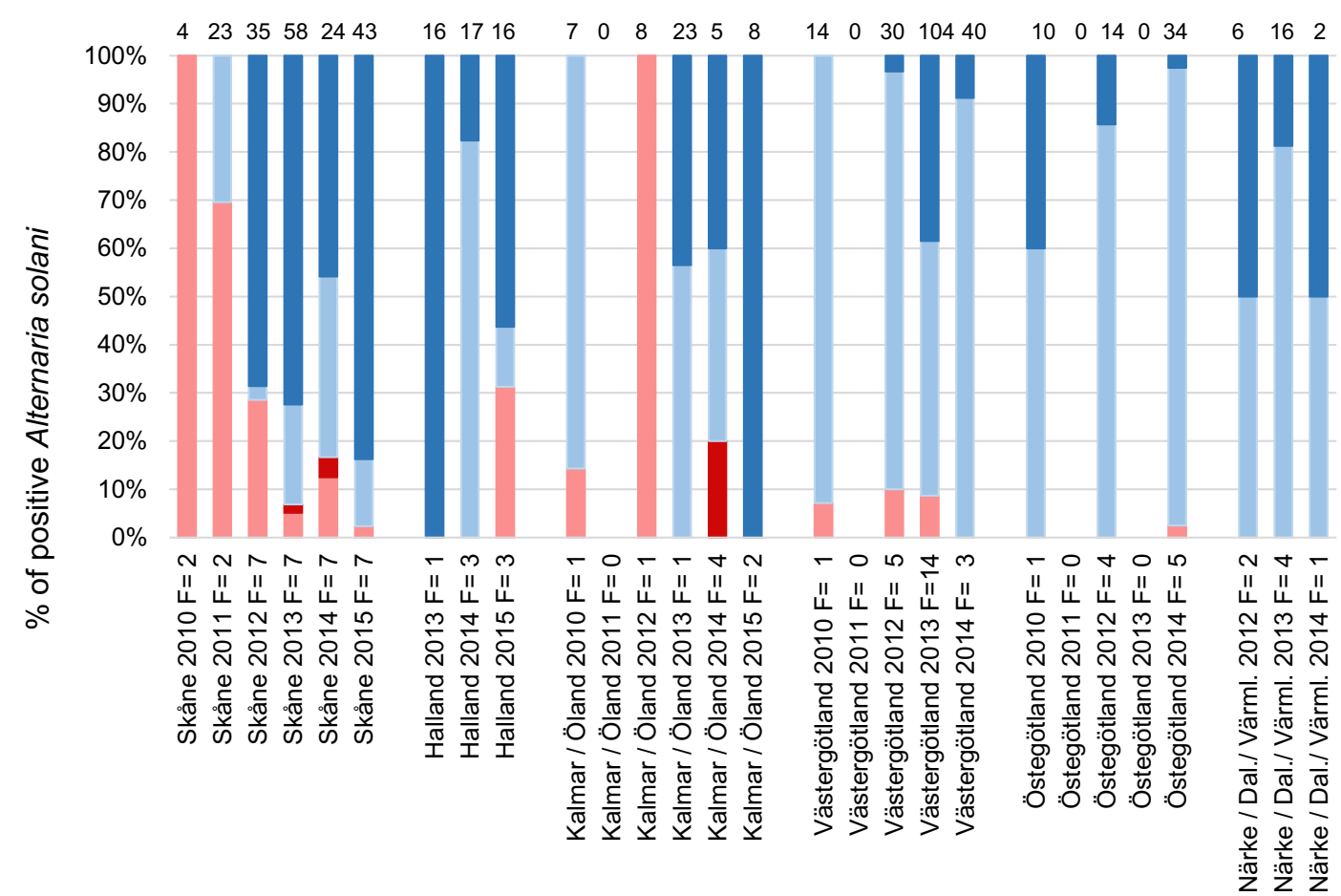

\section{- GI non-mutated GI F129L}

Fig. 3 Proportion of cytochrome $b$ genotype and presence of the amino acid substitution F129 L, associated with loss of sensitivity to fungicides based on strobilurins, among samples positive for Alternaria solani collected in various counties of the southern and central potato production areas in Sweden 2010-2015. The

\section{GII non-mutated $\quad$ GII F129L}

number above the bars represents the total number of positive samples for each region and year, whereas the numbers in the legend represent the number of fields sampled in each region for a particular year 
GI and GII F129 L were found in 2009 at the farm Kalmar B, ca $24 \mathrm{~km}$ west of the farm Öland A where the first sample with GII F129 L was found in 2009. From 2013 onwards, the combination of non-mutant GI and GII F129 L was found in southern Sweden as well as in the central part of Sweden. The samples with double genotypes are excluded in Tables 3 and 6 and all figures, but were regarded as positive for $A$. solani. These samples, originating from five fields collected three times during the season in southern Sweden, were included in the statistical analysis of seasonal changes for $A$. solani (Table 5).

Alternaria alternata possessing the substitution G143A was found in 118 of 204 (58\%) samples from south-eastern Sweden where A. alternata was identified (Table 4). The probability of positive samples possessing G143A substitution increased in the third collection compared to the first $(p<0.0001)$ and second collection $(p=$ 0.0043) (Table 5). Alternaria alternata G143A was recovered from samples origination from an organically cultivated field north of Kristianstad (Kristianstad N:o 2010). That field was located close to a fungicide treated potato crop where A. alternata G143A also was found (Kristianstad N:c 2010). Only non-mutated A. alternata was recovered from the samples obtained from three fields in central Sweden (Table 4).

\section{Alternative host}

Necrotic lesions from black nightshade were examined for both species in 2011 and 2012 and for A. solani in 2015. Alternaria solani was not found in 2011, but one nonmutated A. alternata and one A. alternata G143A was found at the farm Öland A. At the farm Kristianstad D, two non-mutated A. alternata and three A. alternata G143A were recovered from black nightshade in 2011. Both Alternaria species were identified among the samples collected at the farm Kristianstad D in 2012: all three samples positive for A. solani were GII F129 L, while A. alternata possessing the G143A substitution was identified in four of the five lesions analysed. All eight samples from a field on Öland 2015 were A. solani GII F129 L.

\section{Discussion}

Alternaria solani was identified more frequently later in the season, especially from samples collected in September when the disease was established in the starch potato crops in south-eastern Sweden (Tables 3 and 5). Increased incidence of $A$. solani during the season has also been reported from Belgium (Vandecasteele et al. 2018). In central Sweden, disease incidence was low compared to the south, even though the percentage of lesions with confirmed $A$. solani was approximately the same, $44 \%$ in southern Sweden and $47 \%$ in central Sweden. This could be an effect of the selective sampling strategy, since only lesions with symptoms resembling early blight were analysed. One interesting observation was that the symptoms in central Sweden were not as typical for early blight as they were in southern Sweden (Fig. 4), which may be due to cultivar effects or that the climatic factors were more favourable in southern Sweden.

During the 8 years of monitoring, the population of A. solani changed regarding cytochrome $b$ genotype. Genotype GI decreased in abundance in favour of genotype GII, which is now dominating the Swedish population of the pathogen. When considering our results, showing that the shift from non-mutated GII to GII F129 L occurred the year before the shift from GI to GII, regardless of mutation, the genotype change is most probably due to selection caused by strobilurin applications. We found only five samples with GI F129 L. A higher occurrence of F129 L in GII compared to GI has also been observed in Belgium (Landschoot et al. 2017a). It is possible that the intron in the gene encoding the GI genotype has a diminishing effect on the ability to mutate or that GII isolates have a better fitness compared to GI. However, to our knowledge, no such studies are yet reported.

The identification of the F129 L substitution is based on the presence of the nucleotide $\mathrm{A}$ instead of $\mathrm{C}$ in codon 129 in the mitochondrial gene encoding cytochrome $b$. The fungal cell may, however, possess both mutated and non-mutated mitochondria. Further, the mitochondria may be inherited in different ratios and result in isolates that vary in tolerance against strobilurins. (Lesemann et al. 2006; Villani and Cox 2014). During this study, there were a few samples that had peaks of both nucleotides, but they were considered as mutated since the peak of the A-nucleotide was in general higher than the C-nucleotide peak. We did not investigate if the tolerance to azoxystrobin was different in these samples.

Samples with GII were present in all fields in southeastern Sweden already in 2009, but GII F129 L was only found in one sample from beginning of August on the farm Öland A this year. During the following years, 

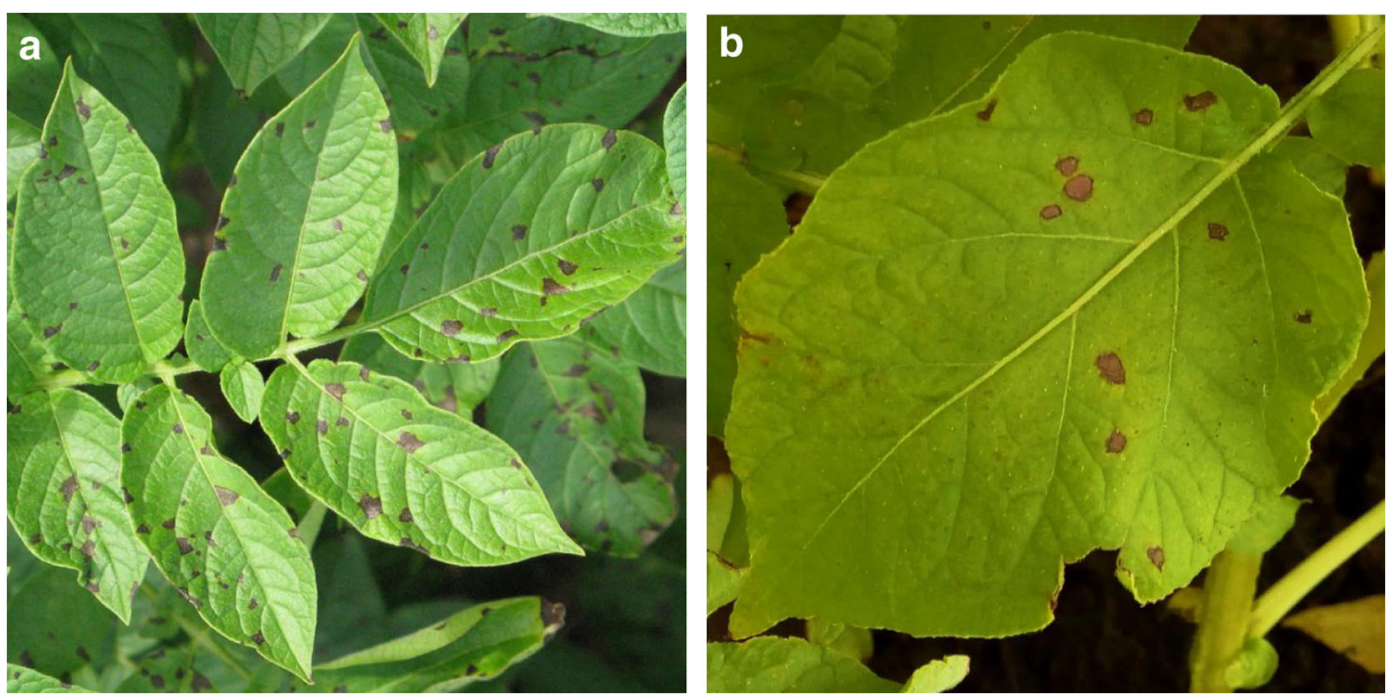

Fig. 4 Symptoms of early blight on starch potato cv Kuras in southern Sweden (a) and lesions on ware potato cv Fakse grown in central Sweden (b), which has not been treated with fungicides against Alternaria solani

a large proportion of the GII-population, especially in south-eastern Sweden, carried the substitution F129 L, which should be a result of selection through strobilurin applications as stated above. The definite shift towards a higher proportion of GII F129 L in southern Sweden appeared between 2011 and 2012, but there were indications that the shift occurred 1 year earlier at the farm Kristianstad D (Fig. 2). The disease incidence is normally high at that location, leading to an intense fungicide use. Similar disease history and management appears at the farm Kalmar B where GII F129 L dominated in 2012. This suggests the high importance of spontaneous local mutations and subsequent selection. As a contrast, one example of possible effects of low disease incidence with less intense fungicide use can be seen in the results from the farm Kristianstad C, where the GI/ GII ratio shifted between years (Fig. 2), which may be a random effect since the samples were taken in a new field each year. Samples with GII F129 L were present in central Sweden when the monitoring started in 2010 but did not dominate within the populations, which may be due to lower disease incidence and less intense fungicide use compared to south-eastern Sweden.

Samples carrying both the GI and GII genotype were frequently found, mainly during the first year of sampling (2009), which coincides with the increase of GII (Table 3 and Suppl. Table 1, Figs. 2 and 3). Multiple infections within the same lesion could explain the presence of both genotypes in a single lesion, but for single spore isolates from the farms Kristianstad C 2011 and Kristianstad E 2014 this cannot be the case. There are no other reports of this phenomena. One possibility is that the intron has been lost in a part of the mitochondrial copies within the cell during the shift towards GII.

Due to the presence of three different F129 L nucleotide substitutions (GI codon CTC and GII codons CTC and TTA), several mutation events must have occurred. Two of these mutations were rarely found, while codon TTA dominated. The considerable distances between the sampling regions indicate further that the substitutions causing strobilurin resistance have occurred locally, similar to what is reported in other plant pathogens (Torriani et al. 2009). The importance of local mutation events is further supported by reports from the US, where various nucleotide substitutions for F129 L in A. solani were observed (Rosenzweig et al. 2008a). Regional and yearly variation in abundance of the F129 L substitution was found within the US populations of A. solani, even though the isolates carrying the substitution have dominated for over a decade (Pasche et al. 2005; Bauske et al. 2018; Rosenzweig et al. 2008b). In a previous study, the Swedish population structure of $A$. solani was shown to be diverse with a population differentiation between the farms Öland A, Kalmar B, Kristianstad C and Kristianstad D (Odilbekov et al. 2016). However, more studies of the population structure are needed to map the distribution and dispersal of the pathogen to understand the origin of the substitutions and the cause of the rapid shift in the cytochrome $b$ genotype. 
The correlation between loss of sensitivity to azoxystrobin and presence of F129 L is strong. Isolates carrying the substitution have often an $\mathrm{EC}_{50}$-value that is far above the threshold level for resistance (Pasche et al. 2005; Landschoot et al. 2017a; Odilbekov et al. 2016). Observations of reduced field efficacy in south-eastern Sweden has been observed in a field trial outside Kristianstad in 2014, where two applications of Amistar (azoxystrobin, Syngenta) resulted in the same disease level as the untreated control (Liljeroth 2016).

The prevalence of A. alternata may be explained by the fact that many of the identified samples collected in August 2011 and 2012 possessed the substitution G143A resulting in a better chance to survive fungicide treatments. However, the practical importance can be discussed considering the low pathogenicity of A. alternata. Both species of Alternaria have been reported on potato under European field conditions and they often coexist in the same field (Hausladen and Leiminger 2007; Vandecasteele et al. 2018). In an Israeli study, A. alternata was determined to cause disease after performing isolation and re-infection according to Koch's postulates (Droby et al. 1984). In that study, it was also shown that A. alternata can infect through the stomata, suggesting that it is a true pathogen. Both A. alternata and A. solani were found in potato fields in Wisconsin, USA, and both species were able to infect attached potato leaves, even though the infections caused by $A$. solani were more severe (Ding et al. 2019). The inoculum load may be important since A. alternata was only able to infect if the spore concentration was high (Böhme et al. 2012). However, other researchers have not been able to induce necrotic lesions by inoculation of A. alternata (Spoelder et al. 2014; Stammler and Tegge 2014; E. Edin, SLU \& A. Lees, TJHI, personal communication; B. Nielsen, AU, personal communication). The high co-occurrence of $A$. solani and A. alternata in the present study implies that A. alternata is a secondary pathogen that may require damaged leaf tissue to be able to infect. Overall, we did not observe any symptoms reported to be caused by A. alternata in our survey (van der Waals 2014).

In many of the sampled lesions, neither A. solani nor A. alternata could be identified. Lesions on potato leaflets and stems can have several physiological causes, which can easily be mistaken for early blight. Nutrient deficiency, especially from manganese, magnesium and potassium, can cause lesions resembling early blight. Ground level ozone may also cause dark brown lesions with concentric rings (Turkensteen et al. 2010). Leaf tissue injuries from abiotic factors can pave the way for secondary pathogens like A. alternata. As a result, A. alternata may falsely be determined as the causal agent in a diagnostic analysis. It is also possible that other small spore Alternaria species like A. arborescens and A. infectoria can either cause or inhabit lesions (Vandecasteele et al. 2018; Kokaeva et al. 2018). Alternaria grandis is the main causal agent of early blight in Brazil, for instance (Rodrigues et al. 2010) and has also been found on Belgian potato crops (Landschoot et al. 2017b). Presence of Alternaria linariae was tested in a previous study but no positive samples were obtained (Odilbekov et al. 2016). Identification of other species of Alternaria was not performed in this study, mainly due to the contemporary opinion of causal agent prior to 2017 when the first European report of other Alternaria species was published.

Occurrence of other Alternaria species among the lesions analysed here could be an issue of the specificity of the primers used for identification of cytochrome $b$ genotype. Both primers for identification of GI have 100\% match to A. solani when using BLASTN on the NCBI home page (National Center for Biotechnology Information, Bethesda, USA). No other Alternaria species were among the top 100 closest BLASTN hits. The primers were tested for A. alternata during development (Edin 2012). The forward GII primer had a perfect match (100\%) with A. alternata, Alternaria mali as well as A. solani, and the reverse GII primer had $100 \%$ match with A. solani and $56 \%$ match with A. alternata when having Alternaria (taxa) as the organism search criteria. One concern is, however, that not all species of Alternaria, like A. grandis, found on potato are published on NCBI. Therefore, we cannot exclude that other species were present among our samples. The primers by Zur et al. (2002) are not species specific for A. alternata and both primers have BLASTN hits on several species of Alternaria at NCBI, among those A. arborescens. The forward primer for G143A has $100 \%$ match for several listed strains of A. alternata and one strain of A. mali at NCBI, whereas the reverse primer is a perfect match on two listed strains of $A$. alternata, enabling reliable analysis.

It is known that black nightshade (Solanum nigrum) can be infected by Alternaria sp. (Abbas et al. 1995; Singh et al. 1998) but it has not been reported in Sweden before. In this study, all samples confirmed with A. solani from nightshade were GII F129 L, which corresponded to the genotype found on the potato crop. Alternaria alternata was found in twelve lesions and eight of them were 
G143A. However, since we did not conduct any reinoculation studies, we cannot be sure that the lesions were originally caused by A. alternata. Pathogenic strains infecting alternative hosts may have different fitness parameters compared to isolates from the crop host. In Phytophthora infestans, the cause of late blight on potato, strains that infect the alternative host hairy nightshade (Solanum physalifolium) were more aggressive on potato (Grönberg et al. 2012). It could be relevant to check if this is the case also for $A$. solani.

In conclusion, the results from this study suggest that the amino acid substitution F129 L, associated with loss of sensitivity toward strobilurins, is widely spread in the Swedish populations of $A$. solani. This information has resulted in a decline in the use of strobilurins, especially as single ingredient, in Sweden after 2015. On the other hand, continued monitoring of fungicide sensitivity of A. solani for fungicides based on other modes of action, as well as genetic studies, will be important tools in the development of efficient control strategies against early blight in Swedish potato production.

Strategies to prevent fungicide resistance need to be prioritised, since loss of efficacy can result in drastic limitations in the possibilities to control diseases like early blight. It is also essential to minimise the environmental impacts of inefficient fungicide treatments. The implementation of integrated pest management (IPM) can be one way of reducing the problems with early blight. Cultivation practices, such as crop rotation, reduce the amount of inoculum in the field and maintaining a good nutritional and water status can improve crop resilience. Decision support systems have the potential to become a useful tool for proper timing and use of reduced fungicide dosages to control early blight in potato (Abuley and Nielsen 2017). Integration of alternative means of disease control as induced resistance and biocontrol into fungicide programmes may further decrease the selection pressure towards fungicide resistance.

Acknowledgements The project was financed by The Swedish Farmers' Foundation for Agricultural Research, SLF (grant numbers H0842015 and H1342054) and the Swedish Board of Agriculture. DNA from single spore isolates originating from two fields was kindly supplied by Dr. Firuz Odilbekov, SLU Alnarp. Dr. Byron Vega, University of Florida, kindly provided the methodology for identifying the G143A substitution. Farmers and advisors, as well as personnel at Lyckeby Starch $\mathrm{AB}$ and The Swedish Board of Agriculture provided field condition information and assisted in the collection of leaflets. The authors wish to thank personnel at the Department of Forest Mycology and Plant Pathology for excellent support of the laboratory work, and Claudia von Brömssen, Dept of Energy and
Technology, Unit of Applied Statistics and Mathematics, SLU, for help with the statistical analyses.

\section{Compliance with ethical standards}

Conflict of interest The authors have not found any potential conflicts of interest and all ethical aspects are considered.

Open Access This article is distributed under the terms of the Creative Commons Attribution 4.0 International License (http:// creativecommons.org/licenses/by/4.0/), which permits unrestricted use, distribution, and reproduction in any medium, provided you give appropriate credit to the original author(s) and the source, provide a link to the Creative Commons license, and indicate if changes were made.

\section{References}

Abbas, H. K., Tanaka, T., Duke, S. O., \& Boyette, C. D. (1995). Susceptibility of various crop and weed species to AALtoxin, a natural herbicide. Weed Technology, 9(1), 125-130.

Abuley, I. K., \& Nielsen, B. J. (2017). Evaluation of models to control potato early blight (Alternaria solani) in Denmark. Crop Protection, 102, 118-128. https://doi.org/10.1016/j. cropro.2017.08.012.

Andersson, B., \& Wiik, L. (2008). Betydelsen av torrfläcksjuka (Alternaria ssp.) på potatis. Final Report SLF 0455031 (In Swedish). Swedish Farmer's Research Foundation.

Bauske, M. J., Mallik, I., Yellareddygari, S. K. R., \& Gudmestad, N. C. (2018). Spatial and temporal distribution of mutations conferring QoI and SDHI resistance in Alternaria solani across the United States. Plant Disease, 102(2), 349-358. https://doi.org/10.1094/PDIS-06-17-0852-RE.

Böhme, F., Miessner, S., Tegge, V., Erven, T., \& Stammler, G. (2012). Pathogenität von Alternaria-Arten an Kartoffeln und Tomaten. In 58th Deutsche Pflanzenschutztagung, "Pflanzenschutzalternativlos" (Vol. Abstract 14-2).

Ding, S., Meinholz, K., Cleveland, K., Jordan, S. A., \& Gevens, A. J. (2019). Diversity and virulence of Alternaria spp. causing potato early blight and Brown spot in Wisconsin. Phytopathology, 109(3), 436 445. https://doi.org/10.1094/phyto-06-18-0181-r.

Droby, S., Dinoor, A., Prusky, D., \& Barkaigolan, R. (1984). Pathogenicity of Alternaria alternata on potato in Israel. Phytopathology, 74(5), 537-542.

Edin, E. (2012). Species specific primers for identification of Alternaria solani, in combination with analysis of the F129L substitution associates with loss of sensitivity toward strobilurins. Crop Protection, 38, 72-73. https://doi.org/10.1016/j. cropro.2012.03.021.

Grasso, V., Palermo, S., Sierotzki, H., Garibaldi, A., \& Gisi, U. (2006). Cytochrome $b$ gene structure and consequences for resistance to Qo inhibitor fungicides in plant pathogens. Pest Management Science, 62(6), 465-472.

Grönberg, L., Andersson, B., \& Yuen, J. (2012). Can weed hosts increase aggressiveness of Phytophthora infestans on potato? Phytopathology, 102(4), 429-433. 
Hausladen, H., \& Leiminger, J. (2007). Potato early blight in Germany (Alternaria solani - Alternaria alternata). In $\mathrm{H}$. Schepers (Ed.), Special report no. 12. PPO publication no. 370 (pp. 189-193). Lelystad.

Ihrmark, K., Johannesson, H., Stenström, E., \& Stenlid, J. (2002). Transmission of double-stranded RNA in Heterobasidion annosum. Fungal Genetics and Biology, 36(2), 147-154. https://doi.org/10.1016/S1087-1845(02)00011-7.

Kokaeva, L. Y., Belosokhov, A. F., Doeva, L. Y., Skolotneva, E. S., \& Elansky, S. N. (2018). Distribution of Alternaria species on blighted potato and tomato leaves in Russia. Journal of Plant Diseases and Protection, 125(2), 205-212. https://doi. org/10.1007/s41348-017-0135-3.

Landschoot, S., Vandecasteele, M., Carrette, J., De Baets, B., Höfte, M., Audenaert, K., et al. (2017a). Assessing the Belgian potato Alternaria population for sensitivity to fungicides with diverse modes of action. European Journal of Plant Pathology, 148(3), 657-672. https://doi.org/10.1007/s10658-016-1123-3.

Landschoot, S., Vandecasteele, M., De Baets, B., Hofte, M., Audenaert, K., \& Haesaert, G. (2017b). Identification of A. arborescens, A.grandis, and A. protenta as new members of the European Alternaria population on potato. Fungal Biology, 121(2), 172-188. https://doi.org/10.1016/j.funbio.2016.11.005.

Leiminger, J., Adolf, B., \& Hausladen, H. (2014). Occurrence of the F129L mutation in Alternaria solani populations in Germany in response to QoI application, and its effect on sensitivity. Plant Pathology, 63(3), 640-650. https://doi. org/10.1111/ppa.12120.

Lesemann, S. S., Schimpke, S., Dunemann, F., \& Deising, H. B. (2006). Mitochondrial heteroplasmy for the cytochrome $b$ gene controls the level of strobilurin resistance in the apple powdery mildew fungus Podosphaera leucotricha (Ell. \& Ev.) E.S. Salmon. Journal of Plant Diseases and Protection, 113(6), 259-266. https://doi.org/10.1007/bf03356191.

Liljeroth, E. (2016). Effekt av azoxystrobin mot torrfläcksjuka. Rapport till Partnerskap Alnarp.

Luo, Y., Ma, Z. H., Reyes, H. C., Morgan, D. P., \& Michailides, T. J. (2007). Using real-time PCR to survey frequency of azoxystrobin-resistant allele G143A in Alternaria populations from almond and pistachio orchards in California. Pesticide Biochemistry and Physiology, 88(3), 328-336. https://doi.org/10.1016/j.pestbp.2007.01.009.

Odilbekov, F. (2015). Resistance to early blight in potato and genetic structure of the pathogen population in Southeast Sweden. Swedish University of Agricultural Sciences, SLU.

Odilbekov, F., Edin, E., Garkava-Gustavsson, L., Hovmalm, H. P., \& Liljeroth, E. (2016). Genetic diversity and occurrence of the F129L substitutions among isolates of Alternaria solani in South-Eastern Sweden. Hereditas, 153(1), 1-10. https://doi.org/10.1186/s41065-016-0014-0.

Pasche, J. S., Piche, L. M., \& Gudmestad, N. C. (2005). Effect of the F129L mutation in Alternaria solani on fungicides affecting mitochondrial respiration. Plant Disease, 89(2), 269-278.

Peters, R. D., Drake, K. A., Gudmestad, N. C., Pasche, J. S., \& Shinners-Carnelley, T. (2008). First report of reduced sensitivity to a QoI fungicide in isolates of Alternaria solani causing early blight of potato in Canada. Plant Disease, 92(12), 17071707. https://doi.org/10.1094/PDIS-92-12-1707B.

Rodrigues, T. T. M. S., Berbee, M. L., Simmons, E. G., Cardoso, C. R., Reis, A., Maffia, L. A., et al. (2010). First report of
Alternaria tomatophila and A. grandis causing early blight on tomato and potato in Brazil. New Disease Reports, 22, Article 28. https://doi.org/10.5197/j.2044-0588.2010.022.028.

Rosenzweig, N., Atallah, Z. K., Olaya, G., \& Stevenson, W. R. (2008a). Evaluation of QoI fungicide application strategies for managing fungicide resistance and potato early blight epidemics in Wisconsin. Plant Disease, 92(4), 561-568. https://doi.org/10.1094/pdis-92-4-0561.

Rosenzweig, N., Olaya, G., Atallah, Z. K., Cleere, S., Stanger, C., \& Stevenson, W. R. (2008b). Monitoring and tracking changes in sensitivity to azoxystrobin fungicide in Alternaria solani in Wisconsin. Plant Disease, 92(4), 555-560. https://doi.org/10.1094/pdis-92-4-0555.

Singh, R. P., Singh, B. D., Singh, R. B., \& Singh, H. B. (1998). Screening of somaclonal variants Solanum nigrum for Alternaria blight resistance. Journal of Medicinal and Aromatic Plant Sciences, 20(3), 712-716.

Spoelder, J., Ellens, R. H., \& Turkensteen, L. J. (2014). Comparing pathogenicity of Alternaria solani to Alternaria alternata. In H. Schepers (Ed.), 16th EuroBlight workshop, Limassol, Cyprus, 2014 (Vol. PPO 568, pp. 97-102, Vol. PPO- Special Report no 16): WageningenUR.

Stammler, G., \& Tegge, V. (2014). Pathogenicity of Alternaria species on tomatoes and potatoes. In H. Schepers (Ed.), 16th EuroBlight workshop, Limassol, Cyprus, 2014 (Vol. PPO 568, pp. 85-96, Vol. PPO- special report no 16): WageningenUR.

Torriani, S. F., Brunner, P. C., McDonald, B. A., \& Sierotzki, H. (2009). QoI resistance emerged independently at least 4 times in European populations of Mycosphaerella graminicola. Pest Management Science, 65(2), 155-162. https://doi. org/10.1002/ps.1662.

Turkensteen, L. J., Spoelder, J., \& Mulder, A. (2010). Will the real Alternaria stand up please? Experiences with Alternaria-like diseases on potatoes during the 2009 growing season in the Netherlands. In H. Schepers (Ed.), Special report no. 14. PPO publication no. 396 (pp. 161-164). Lelystad.

van der Waals, J. E. (2014). Alternaria alternata population study in relation to management of brown spot ("malroes"). http://www. potatoes.co.za/SiteResources/documents/Alternaria\%20 alternata $\% 20$ population $\% 20$ study $\% 20$ in $\% 20$ relation $\% 20$ to $\% 20$ management $\% 20$ of $\% 20$ brown $\% 20$ spot $\% 20 \% 28$ malroes\%29.pdf. Accessed 1 Apr 2019.

Vandecasteele, M., Landschoot, S., Carrette, J., Verwaeren, J., Höfte, M., Audenaert, K., et al. (2018). Species prevalence and disease progression studies demonstrate a seasonal shift in the Alternaria population composition on potato. Plant Pathology, 67(2), 327-336. https://doi.org/10.1111/ppa.12734.

Vega, B., \& Dewdney, M. M. (2014). Distribution of Qol resistance in populations of tangerine-infecting Alternaria alternata in Florida. Plant Disease, 98(1), 67-76. https://doi.org/10.1094/pdis-04-13-0449-re.

Villani, S. M., \& Cox, K. D. (2014). Heteroplasmy of the cytochrome $b$ gene in Venturia inaequalis and its involvement in quantitative and practical resistance to Trifloxystrobin. Phytopathology, 104(9), 945-953. https://doi.org/10.1094 /phyto-06-13-0158-r.

Zur G, Shimoni E, Hallerman E, \& Kashi Y (2002) Detection of Alternaria fungal contamination in cereal grains by a polymerase chain reactionbased assay. Journal of Food Protection, 65(9), 1433-1440. 